\title{
EDITORIAL
}

\section{Antibiotics get their day}

\author{
The increasing problem of antibiotic resistance is regarded as a serious threat to public \\ health. Can education help to preserve the effectiveness of antibiotics?
}

When antibiotics were first introduced into widespread clinical use in the 1950s, it was generally thought that bacterial diseases no longer constituted a public health threat. With the emergence of new infectious diseases and the worrying rise of antibiotic resistance, this early optimism has long since been eroded. Alexander Fleming, the Scottish scientist who won a Nobel prize in 1945 for his discovery of the first antibiotic, penicillin, in 1928, cautioned during his Nobel lecture that "the time may come when antibiotics can be bought by anyone in the shops. Then there is the danger that the ignorant man may easily underdose himself, and by exposing his microbes to non-lethal quantities of the drug, make them resistant." (REF. 1)

Every antibiotic that is introduced into clinical use has a limited shelf life owing to the selection of antibioticresistant bacteria, which can eventually predominate if selection pressure is applied by the continued presence of the antibiotic. The increase in the number of resistant organisms has become a huge problem, with multidrugresistant Acinetobacter baumannii and Klebsiella pneumoniae isolates becoming virtually untreatable with currently available antibiotics. Resistance to antibiotics is therefore more of a problem than ever and is even touted by some as an emergent disease.

Although researchers are continually striving to identify new targets for antibiotics, the path from a promising lead compound to a drug that is available for clinical use is a long and difficult one. Now, taking a different approach, the European Centre for Disease Control (ECDC), in close alliance with the WHO, has launched an annual event European Antibiotic Awareness Day - to raise awareness about the risks associated with the inappropriate use of antibiotics and show how to take antibiotics responsibly. The inaugural event was held on 18 November 2008, and Zsuzsanna Jakab, the director of the ECDC, commented: "antibiotic resistance is one of the biggest threats to public health in the European Union. If the misuse and overuse of antibiotics continue, we will lose the means to treat serious infectious diseases." This is a welcome attempt to educate the public with practical advice and information that might help in the fight to reduce the scale of the resistance problem. In addition to the global issue of antibiotic resistance, prescribing practices have come under fire. Christopher Butler (Cardiff University, Wales), a professor of primary-care medicine, noted that "in the Grace Study, funded by the European Union, we found huge differences in the amount of antibiotics prescribed between countries that can't be explained away by differences in patients symptoms." However, although over-prescribing might be wasteful, the evidence that amending prescription practices can reduce the emergence of resistance has been questioned ${ }^{2}$ and understanding how resistance arises and evolves from the resistome in the environment is of prime importance ${ }^{3}$.

Twenty-seven European Union (EU) member states participated in the event. Posters (including several slogans, of which our favourite is 'Unfortunately, no amount of antibiotics will get rid of your cold', which highlights the key principle that antibiotics must not be wasted treating non-bacterial infections) were available to distribute to schools, hospitals, medical surgeries and pharmacies throughout the EU. In the United Kingdom, a conference was held for health-science journalists and health professionals at the Science museum in London that had the immediate effect of spawning news items about the misuse of antibiotics in widely read daily newspapers. The conference also drew attention to resources for teachers, including a free online schools programme named e-Bug that comprises lesson plans, activity sheets and games to educate children about antibiotic use and misuse. The European Parliament in Strasbourg marked the event with a scientific seminar for MEPs (members of the European parliament) held on European Antibiotic Awareness Day. Presentations given by EU Health Commissioner, Androulla Vassiliou, French Director-General for Health, Didier Houssin, Director of the European Centre for Disease Prevention and Control, Zsuzsanna Jakab, and Benoît Schlemmer provided the latest EU-wide surveillance data and made a case for rational antibiotic use.

We hope that initiatives such as European Antibiotic Awareness Day can provide the impetus needed to tackle the global burden of antibiotic resistance.

\footnotetext{
Fleming, A. Penicillin. Nobel Lecture, December 11, 1945. Nobel Prize.org [online], http://nobelprize.org/nobel_prizes/medicine/ laureates/1945/fleming-lecture.pdf.

2. Livermore, D. Can better prescribing turn the tide of resistance? Nature Rev. Microbiol. 2, 73-78 (2004).

3. Wright, G. D. The antibiotic resistome: the nexus of chemical and genetic diversity. Nature Rev. Microbiol. 5, 175-186 (2007).
} 